Melissa Costa Santos ${ }^{1}$

Charles Dalcanale Tesser ${ }^{2}$

\title{
Um método para a implantação e promoção de acesso às Práticas Integrativas e Complementares na Atenção Primária à Saúde
}

\author{
A method for the implementation and promotion of access \\ to comprehensive and complementary primary healthcare practices
}

${ }^{1}$ Programa de Pós-

Graduação em Saúde

Coletiva. Universidade

Federal de Santa Catarina

(UFSC). Av. Professor

Henrique da Silva Fontes

6100, Trindade. 88036-700

Florianópolis SC.

melcostasantos@gmail.com

${ }^{2}$ Departamento de Saúde

Pública, Centro de Ciências

de Saúde, Universidade

Federal de Santa Catarina.

\begin{abstract}
The rendering of integrated and complementary practices in the Brazilian Unified Health System is fostered to increase the comprehensiveness of care and access to same, though it is a challenge to incorporate them into the services. Our objective is to provide a simple method of implementation of such practices in Primary Healthcare, derived from analysis of experiences in municipalities, using partial results of a master's thesis that employed research-action methodology. The method involves four stages: $1-$ defininition of a nucleus responsible for implementation and consolidation thereof; 2 - situational analysis, with definition of the existing competent professionals; 3 - regulation, organization of access and legitimation; and 4 -implementation cycle: local plans, mentoring and ongoing education in health. The phases are described, justified and briefly discussed. The method encourages the development of rational and sustainable actions, sponsors participatory management, the creation of comprehensivenessand the broadening of care provided in Primary Healthcare by offering progressive and sustainable comprehensive and complementary practices.
\end{abstract}

Key words Health management, Complementary therapies, Comprehensive medicine, Health policy
Resumo A oferta de Práticas Integrativas e Complementares no Sistema Único de Saúde é estimulada para ampliar a integralidade da atenção e o acesso às mesmas, mas é um desafio incorporá-las aos serviços. Nosso objetivo é apresentar um método de implantação das PIC na Atenção Primária à Saúde, derivado da análise de experiências municipais, resultado parcial de estudo de mestrado cuja metodologia foi a pesquisa-ação. O método envolve 4 fases: 1 - definição do núcleo responsável pela implantação e sua solidificação; 2 análise situacional, com mapeamento de profissionais competentes já existentes; 3 - regulamentação, organização do acesso e legitimação; 4 - ciclo de implantação: pactuação de planos locais, tutoria e atividades de educação permanente em saúde. As fases são descritas, fundamentadas e sucintamente discutidas. O método estimula o desenvolvimento de ações racionais e sustentáveis, fomenta a gestão participativa, a construção da integralidade e a ampliação responsável do cuidado realizado na Atenção Primária à Saúde através da oferta progressiva e sustentável de Práticas Integrativas e Complementares.

Palavras-chave Gestão em saúde, Terapias complementares, Medicina integrativa, Política de saúde 


\section{Introdução}

A incorporação das Medicinas Alternativas e Complementares/Tradicionais, chamadas pelo governo brasileiro de Práticas Integrativas e Complementares (PIC) ${ }^{1}$, na rede pública de saúde brasileira está em lenta expansão. Além das recomendações da Organização Mundial de Saúde para que os países elaborem políticas que considerem o acesso a estas práticas, há um contexto mundial favorável a isso, devido, entre outros fatores, ao abalo da biomedicina nas suas relações com os usuários, a sua tendência ao uso abusivo de tecnologias duras, a seus efeitos iatrogênicos e a uma significativa "desumanização" das suas práticas profissionais ${ }^{2-4}$. Complementarmente, parte do crescimento da procura social pelas PIC deve-se a méritos próprios: reposicionam o paciente como centro do paradigma médico; consideram a relação curador-paciente como elemento fundamental da terapêutica; buscam meios terapêuticos simples, menos dependentes de tecnologia científica dura, menos caros e, entretanto, com igual ou maior eficácia nas situações comuns de adoecimento; e estimulam a construção de uma medicina que busca acentuar a autonomia do paciente, tendo como categoria central a saúde e não a doençâ ${ }^{3,5-9}$.

No Brasil, as discussões sobre esse tema iniciaram-se na década de 1980, coincidindo com a criação do Sistema Único de Saúde (SUS), com destaque para a $8^{\text {a }}$ Conferência Nacional de Saúde, em 1986, que deliberou a introdução de práticas alternativas de assistência à saúde no âmbito dos serviços de saúde ${ }^{1}$. Na década de 1990, o grupo de pesquisa Racionalidades Médicas, liderado por Madel Luz, evidenciou-se discutindo inicialmente sistemas médicos complexos (homeopatia, medicina tradicional chinesa e ayurvédica) e depois práticas de saúde, em sua diversidade de saberes e práticas ${ }^{10}$, fortalecendo o movimento ainda tímido de inserção das PIC na saúde pública brasileira. Contudo, o marco ocorreu em 2006, com a edição da Política Nacional de PIC (PNPIC), a qual enfatiza a inserção das PIC na atenção primária à saúde (APS), contribuindo para o aumento da resolubilidade do sistema, com um cuidado continuado, humanizado e integral ${ }^{1}$ e visando também normatizar a utilização destas práticas no SUS (já que em todas as práticas heterônomas de saúde pode-se observar comportamentos inadequados, tais como imprudência profissional e manipulação da indústria e propaganda, o que é facilitado pela ausência de regulamentação) ${ }^{3}$. A PNPIC contri- bui também para a ampliação do acesso às PIC ${ }^{1,11}$, já que, até então, estas práticas estavam mais restritas ao setor privado, reconhecendo a pluralidade nos cuidados ${ }^{12}$ e possibilitando outros saberes e racionalidades, com ampliação da variedade de recursos para a atenção à saúde ${ }^{13,14}$.

Por outro lado, considera-se um desafio aos gestores públicos a efetiva institucionalização das PIC no SUS, já que os atuais mecanismos legais não são suficientes quando há reduzido número de recursos humanos capacitados, insuficiente financiamento para a maioria das práticas e poucos espaços institucionais para desenvolvimentos de novas práticas e serviços ${ }^{2,7}$, além de fatores culturais e científicos que frustram as tentativas de integração das PIC à biomedicina ${ }^{15}$. Reconhece-se a importância do estabelecimento de uma política, porém há carência de diretrizes operacionais para implantação das PIC, o que dificulta a consolidação dessas práticas, especialmente na APS. O objetivo deste artigo é apresentar e fundamentar um método para a implantação e promoção de acesso às PIC na APS, contribuindo na qualificação e ampliação do cuidado e da resolubilidade na APS e disponibilizando um instrumento de orientação para a gestão local.

\section{Metodologia}

O método aqui apresentado deriva da análise da experiência em andamento em Florianópolis (SC), complementada com experiência prévia do município de Campinas (SP), em que um dos autores trabalhou em 2003-2005. Tal análise se insere numa pesquisa de mestrado em Saúde Coletiva, aprovada pelo Comitê de Ética em Pesquisa sobre Seres Humanos da Universidade Federal de Santa Catarina, cuja metodologia foi a pesquisa-ação, em que há estreita relação entre pesquisadores e pessoas da situação investigada do tipo participativo ${ }^{16}$. Por meio de seminários de pesquisa, gera-se aumento do "nível de consciência" do grupo envolvido, constatações de dificuldades, discussão de valores, investigações, decisões, experimentações e avaliações a fim de solucionar um problema coletivo ${ }^{16,17}$, que, no nosso caso, relacionou-se à implantação das PIC na APS. Analisando este processo, puderam ser extraídas diretrizes de ação potencialmente aplicáveis e ou adaptáveis em outros contextos.

O campo empírico foi o município de Florianópolis, com 421.203 habitantes, em que a Estratégia de Saúde da Família cobre $90 \%$ da população, com cinco Distritos Sanitários, 112 equi- 
pes de saúde da família atuando em 50 Centros de Saúde e 7 Núcleos de Apoio a Saúde da Família (NASF), nos quais o município optou por não incluir acupunturistas e homeopatas. Apesar de haver dois médicos acupunturistas e um homeopata nas Policlínicas Municipais como referência à APS, não existia, no início da pesquisa, apoio institucional para a oferta de PIC na APS.

A investigação foi conduzida por um núcleo de pesquisadores, como orienta a pesquisa-ação, formado pelos membros ativos da Comissão de PIC da Secretaria Municipal de Saúde, constituída em março de 2010, e que incluía os autores do artigo. Os dados foram registrados e analisados durante os seminários por um ano e meio (abril/ 2010 a outubro/2011), período em que desenvolveram-se os ciclos de pesquisa-ação, compostos por quatro momentos: exploratório; principal ou de planejamento; de ação; e de avaliação $0^{17}$.

Nos seminários identificou-se problemas e prioridades, colheu-se informações, planejou-se e realizou-se ações e avaliações das mesmas, visando implantar e promover o acesso às PIC na APS. A partir da experiência vivida e registrada (diário de campo), dos dados gerados pelos trabalhos da Comissão (atas, relatórios e documentos institucionais) e da sua análise pelos pesquisadores, extraiu-se, num esforço de síntese e abstração, diretrizes estratégicas e metodológicas que resultaram no método ora apresentado. A Tabela 1 apresenta o número de encontros realizados em cada uma das fases do processo, identificadas em análise retrospectiva, descritas adiante.

Devido a opção do município de priorizar enfaticamente a implantação das PIC na APS, em conformidade com a PNPIC ${ }^{1}$ e a "vocação natural" das PIC para ali se fazerem presentes ${ }^{18-20}$, a discussão realizada atém-se a esse ambiente de serviços. Entretanto, parece-nos que o método é adaptável para outros locais de cuidado, dada sua generalidade e pressupostos, que transcendem a APS.

\section{Apresentação do método}

Experiências no SUS têm mostrado a ineficácia de tentativas de estabelecer novos programas, serviços e reorganizar processos de trabalho sem que sejam questionados segmentos além da gestão ${ }^{21}$. Por isso, as atuais políticas fomentam a gestão participativa e propostas afins, como a de cogestão de Campos ${ }^{22,23}$, contribuem no processo de mudança organizacional e das práticas. Isso é importante para minimizar uma tendência comum nos poderes executivos federais, estaduais e municipais da saúde: protagonizar e personalizar a implantação de políticas, programas ou inovações nos serviços, por motivos de capitalização política e eleitoral, por motivos de apoio genuíno às propostas, ou por ambos. Quando um gestor viabiliza a implantação de ações ou serviços (como as PIC) não é raro que não se construa sustentabilidade cultural, administrativa e política junto a instituição, seus profissionais e a sociedade civil (incluindo o Conselho Municipal de Saúde), a fim de enraizar socialmente e institucionalmente as iniciativas e tornálas imunes à ciclicidade das mudanças dos governantes. Tal ciclicidade dificulta a consolidação de boas práticas gestoras e de cuidado e um dos eixos fundantes do método proposto é uma preocupação constante com o permanente diálogo, a transparência e a negociação entre os envolvidos, de modo a enriquecer a experiência sobre o tema da organização como um todo, visando construir solidez e sustentabilidade social, institucional e política, dadas as dificuldades culturais e organizacionais envolvidas ${ }^{24}$.

O método compõe-se de quatro fases, separadas didaticamente a fim de facilitar a compreensão do processo: 1: Estabelecimento de responsáveis; 2: Análise situacional; 3: Regulamentação; 4: Implantação. A Figura 1 apresenta o modelo lógico do método e, não por acaso, o desenho é semelhante à própria pesquisa-ação, devido a

Tabela 1. Número de reuniões e seminários realizados pelo núcleo responsável pelo processo de implantação das Práticas Integrativas e Complementares no município de Florianópolis/SC, no período de abril de 2010 a outubro de 2011.

\begin{tabular}{lccc}
\hline & $\begin{array}{c}\text { Reuniões/Seminários } \\
\text { do núcleo responsável }\end{array}$ & $\begin{array}{c}\text { Seminários do núcleo } \\
\text { responsável e profissionais }\end{array}$ & $\begin{array}{c}\text { Seminários do núcleo } \\
\text { responsável e gestores }\end{array}$ \\
\hline Fase 1: Estabelecimento de Responsáveis & 4 & 0 & 0 \\
Fase 2: Análise Situacional & 3 & 4 & 1 \\
Fase 3: Regulamentação & 5 & 1 & 4 \\
Fase 4: Implantação & 20 & 1 & 7 \\
Total & 32 & $\mathbf{6}$ & 12 \\
\hline
\end{tabular}




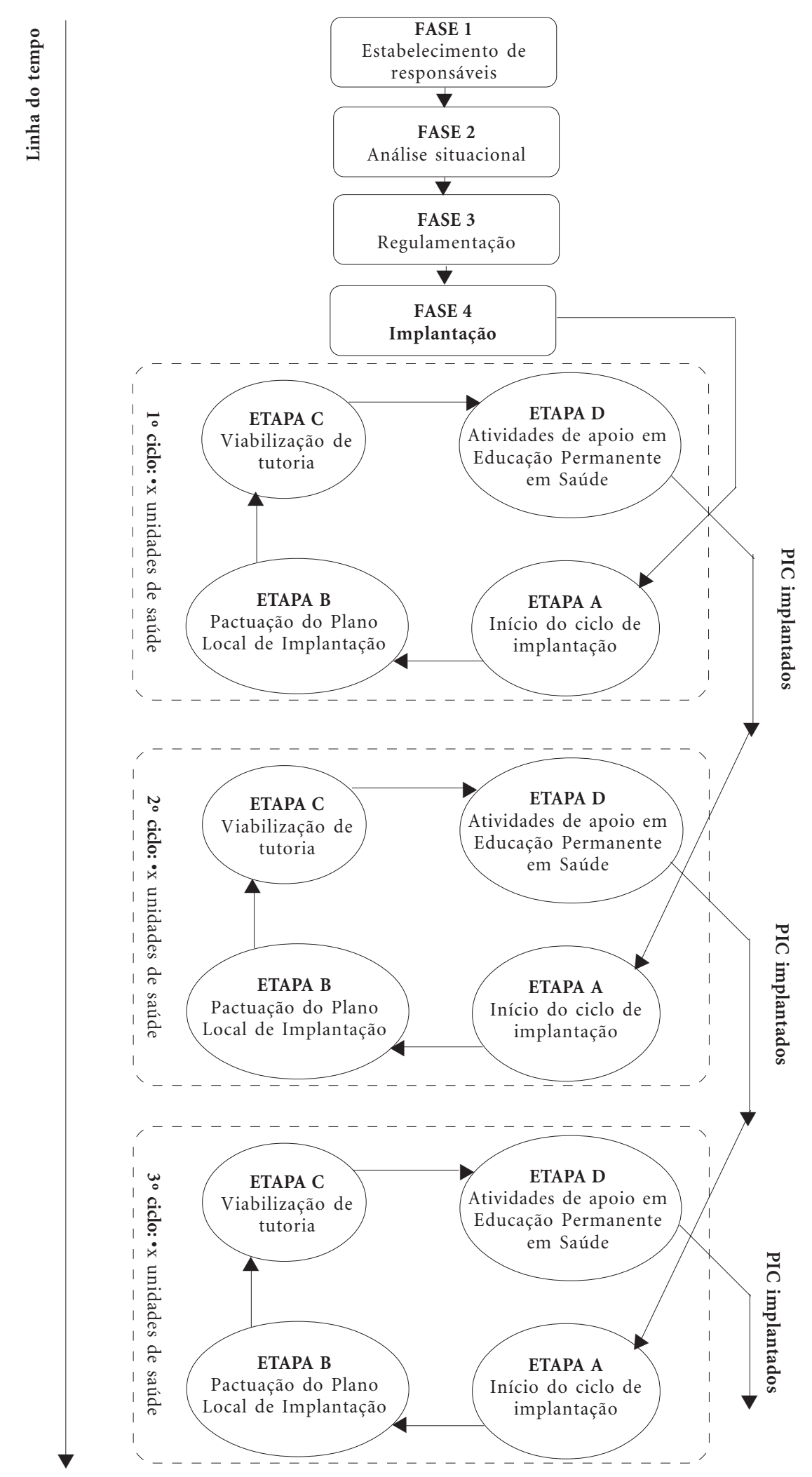

Figura 1. Modelo lógico do método de implantação e promoção do acesso às Práticas Integrativas e Complementares (PIC) na Atenção Primária à Saúde. 
valores comuns a ambos: participação, permanente negociação, diálogo, consensuação e corresponsabilização, favorecendo implantação progressiva e sustentável, com estímulo ao aprendizado organizacional, o que é também proposto por Campos $^{22,23}$ e Rivera e Artmann ${ }^{24}$.

\section{Fase 1 - Estabelecimento de Responsáveis}

O primeiro passo é a definição de um núcleo responsável pela condução do processo, podendo ser constituído por profissionais da instituição, preferencialmente de caráter multiprofissional e com expertises em variadas PIC. É recomendável que a responsabilidade não fique exclusivamente em uma única pessoa, o que poderia centralizar politica e administrativamente o processo, diminuindo o aprendizado institucional. Mas em municípios de pequeno porte talvez isso não seja possível, quando recomenda-se a identificação de profissionais em municípios vizinhos consorciados ou "consorciáveis". Pode-se também convidar especialistas, acadêmicos ou assessores externos, proporcionando enriquecimento com outras vivências. Nas experiências analisadas, os núcleos eram compostos por um coordenador, que era o mediador principal com demais setores instituicionais do SUS e da sociedade (num caso era um médico deslocado 20 horas para essa função e noutro caso uma farmacêutica que atuava em outras funções da gestão), e os demais membros eram profissionais com competência em alguma PIC, atuantes na APS ou em outros serviços do SUS, de várias categorias profissionais e diferentes territórios, de modo a aumentar a interface de contato com a realidade institucional.

A importância do estabelecimento do núcleo responsável é a representatividade profissional e o diálogo facilitado com os demais atores envolvidos, fomentando a cogestão ao construir espaços de reflexão em que o problema é colocado, a partir do engajamento na análise e deliberação coletivas $^{21}$. Embora a definição do núcleo não necessite vir de um ato institucional, isso legitima as ações do grupo, que assume caráter permanente, ainda que periodicamente sejam repactuados os membros, a fim de garantir a continuidade das ações na área. O núcleo pode assumir atribuições como: propor normatização local, assessoria técnica, atividades educativas, fomento de estudos e pesquisas, etc. As primeiras reuniões podem ter (e tiveram, no nosso caso) caráter de solidificação do grupo, compartilhamento de conhecimentos e experiências, estudo de lite- ratura pertinente, de experiências de outros municípios e da própria PNPIC. Sugere-se a elaboração de um plano de ação mínimo, pactuandose um cronograma de atividades e periodicidade de reuniões, a fim de cumprir com as atribuições e prazos determinados pelos gestores. Nos casos analidados, as reuniões variaram de semanais a quinzenais, ou mais distantes, quando entremeadas por outras atividades de sensibilização e educativas, conforme descrito adiante, com duração de 2 a 3 horas.

\section{Fase 2 - Análise Situacional}

O pressuposto desta fase é uma constatação generalizada em municípios de grande porte e comum em municípios de médio e pequeno porte: o fato de que as PIC despertam interesse social e também em profissionais de saúde, que cada vez mais procuram formação nelas para enriquecimento do seu potencial de cuidado ${ }^{25-28}$ (compreensão dos adoecimentos e ampliação de recursos e técnicas terapêuticas) e de promoção ${ }^{29}$ / prevenção. Isso vem ocorrendo independentemente da gestão do SUS capacitar, incentivar ou contratar profissionais habilitados em PIC. É, portanto, um fenômeno social que precede e transcende as políticas e que pode e deve ser aproveitado.

Por isso, o ponto fundador desta fase é que os principais catalizadores, organizadores e promotores do acesso às PIC nos serviços de saúde municipais já provavelmente existam e estão exercendo outras funções. Ou seja, pessoas que se capacitaram por interesse pessoal e que não exercem tais práticas por desestímulo institucional ou outros motivos. O que se observou nas duas experiências é que um começo promissor consiste no reconhecimento, valorização, diálogo e empoderamento desses profissionais para que não só possam praticar o que sabem em termos de PIC, mas também que contribuam com sua expertise na sensibilização e capacitação de seus colegas na implantação das PIC.

Assim, sugere-se que o núcleo responsável realize um mapeamento dos profissionais capacitados em PIC, atuantes ou não, conforme unidades de saúde e competências específicas, estruturado de forma a facilitar a consulta e a atualização dos dados, já que a flutuação de profissionais nos serviços pode ser comum. A partir desses profissionais, iniciam-se as discussões de implantação e acesso, por meio de seminários que podem, conforme o número de profissionais ser organizados por temas e conduzidos por algu- 
mas questões norteadoras: quais as dificuldades e impeditivos para atuação das PIC na APS? Qual seria a melhor estratégia de organização do processo de trabalho, do fluxo de atendimento e do acesso na APS (atendimento só da área de abrangência, colaboração horizontal, matriciamento)? Como as atividades poderão ser registradas e formalizadas? Uma pesquisa brasileira mostrou haver pelo menos três modos de inserção das PIC "naturalmente" desenvolvidos por profissionais na APS em situação de ausência de apoio institucional ${ }^{30}$ : reserva de turno(s) específico(s) para a prática; integração com demais atividades da APS e ambas as formas associadas.

A mesma dinâmica participativa pode ser adotada em seminários com os gestores e representantes da sociedade a fim de problematizar e compreender as dificuldades relacionadas à promoção do acesso e implantação das PIC. Ao final dos seminários, recomenda-se que sejam registrados os tópicos importantes, na visão de cada esfera (profissionais, gestores e sociedade), que, juntamente com o mapeamento de profissionais, compõem uma síntese da análise situacional das PIC no município. No caso de não haver profissional praticante ou capacitado nos serviços, sugere-se identificar profissionais interessados no tema para essa fase.

\section{Fase 3 - Regulamentação}

A regulamentação surge da necessidade de legitimação profissional e institucional, muito comum em ambientes com gestores não sensíveis às PIC, o que desestimula ou mesmo impossibilita a atuação profissional. A regulamentação pode se dar por uma política municipal, com trâmites legais próprios, ou, de forma mais simples, por ato institucional do gestor municipal, estabelecendo normas gerais para o desenvolvimento das PIC, em consonância com a PNPIC, tais como: fluxos de acesso aos usuários, organização da demanda, estruturação dos serviços e do processo de trabalho das equipes, registros de atendimentos e procedimentos, disponibilização de medicamentos e insumos relacionados, processos educativos e de participação social, etc. O ponto de partida para a elaboração do documento normativo poderá ser o produto da fase anterior, ampliando a discussão em todas instâncias. Por exemplo, em Florianópolis, como resultado das discussões e negociações, definiuse que os profissionais da APS capacitados po- deriam reservar até dois turnos de trabalho para praticar alguma PIC somente aos seus usuários adscritos. Já em Campinas - àquela época - decidiu-se organizar colaboração horizontal entre Centros de Saúde, em que profissionais com competência, além de poderem atender sua própria clientela, reservariam alguns horários para atendimentos oriundos de unidades vizinhas, sendo referência para elas.

Considerando a diversidade profissional na APS, em Florianópolis foi refutada a padronização das atividades. Consensuou-se que o profissional capacitado elaborasse uma pequena proposta de atuação para ciência e acordo de suas coordenações, sem prejuízo de suas demais atividades, atribuições e responsabilidades, de forma que a inclusão das PIC contribuísse para a sua prática e não fosse compreendida como uma sobrecarga de trabalho. O Quadro 1 apresenta uma sugestão de Formulário de Atuação em PIC, que poderá estar como anexo à regulamentação municipal, permitindo a sistematização dos dados de profissionais atuantes na APS e a viabilização das necessidades específicas solicitadas.

Durante esta fase e ao longo do processo de implantação, algumas adequações institucionais podem ser necessárias a fim de possibilitar o monitoramento e a avaliação das atividades, com geração de importantes relatórios institucionais. Por exemplo, é necessária a atualização do Cadastro Nacional de Estabelecimentos de Saúde, incluindo as unidades de saúde que disponibilizarão PIC. Também o registro do atendimento em PIC realizado deverá ser estimulado, conforme códigos definidos pelo Ministério da Saúde ou códigos próprios quando esses não existirem. Complementarmente, sugere-se a checagem da situação das legislações gerais ou específicas sobre as PIC, incluindo a regulamentação dos conselhos profissionais. Podem ocorrer casos de práticas não regulamentadas, em que os gestores e fóruns competentes, notadamente os Conselhos Municipais de Saúde, podem ser corresponsáveis no processo de avaliação e possível legitimação socioinstitucional dos mesmos.

Recomenda-se a aprovação da versão final da normatização municipal em um encontro com profissionais e gestores, que ainda poderá ser submetida a consulta pública e aceitação do Conselho Municipal de Saúde, para que, após formatação e adequação judicial, o secretário municipal de saúde possa aprovar e encaminhar à publicação. 
Profissional requerente:

Profissão:

PIC requerida: (anexar documentos comprobatórios da formação profissional)

PROPOSTA DE ATUAÇÃO (descrever detalhadamente como a PIC será realizada, em que periodicidade, público-alvo, tempo para realização, necessidade de materiais, etc)

(Assinatura e carimbo do profissional)

Ciente e de acordo,

(Assinatura e carimbo da chefia imediata)

Ciente e de acordo,

(Assinatura e carimbo do Diretor do Distrito Sanitário)

\section{Fase 4 - Implantação}

A fase de implantação é fundamental para a expansão sustentável das PIC na APS, já que somente a regulamentação não garante isso. A implantação progressiva tende a favorecer os processos de mudança ${ }^{31}$, por isso essa fase tem caráter descentralizado, com apropriação democrática dos processos de gestão e atendendo às especificidades locorregionais ${ }^{21}$, considerando que isso influencia na qualidade dos serviços ${ }^{32}$, e propõe-se que seja desenvolvida de forma contínua e cíclica. Em cada ciclo trabalha-se algumas poucas unidades de saúde, desenvolvendo-se quatro etapas: Etapa A - Início do ciclo de Implantação; Etapa B - Pactuação do Plano Local de Implantação; Etapa C - Viabilização de tutoria; Etapa D - Atividades de apoio relacionadas à Educação
Permanente em Saúde. A capacidade produtiva do núcleo responsável definirá a velocidade de implantação e, somente após o primeiro ciclo de unidades estarem com suas atividades em PIC bem estruturadas, expande-se a implantação das PIC para um ciclo de novas unidades de saúde.

\section{Etapa A - Início do ciclo de Implantação}

Inicialmente, recomenda-se um encontro com profissionais e gestores, a fim de divulgar a regulamentação, oficializando o início do processo de implantação com ampla discussão sobre diretrizes de ação para promoção, sensibilização e apoio às PIC. Isso é importante para que todos os profissionais interessados e já capacitados se sintam legitimados, conheçam os novos fluxos institucionalizados e se comprometam 
com o processo, já que os espaços coletivos são uma estratégia de democratização das relações de poder, garantindo aos trabalhadores o acesso à informação e o tempo necessário aos processos de discussão, deliberação e planejamento ${ }^{21}$. O produto dessa discussão coletiva poderá ser diretrizes de ação que nortearão o planejamento do núcleo responsável, e não exatamente um plano de ação padrão, já que nossas experiências têm demonstrado que a estratégia de desenvolver um plano de implantação específico para cada unidade de saúde, considerando suas características de população, territórios e equipes, favorece a sustentabilidade das PIC. Isso porque as necessidades e demandas devem ser compreendidas à luz da realidade de cada serviço, considerando seus profissionais, condições sociais, organizacionais e especificidades, devendo ser realizado um processo de construção conjunta, com corresponsabilização ${ }^{31,33}$.

Nesta etapa, pactua-se quais e quantas unidades de saúde integrarão o ciclo. Sugere-se, com base nas experiências observadas, que os primeiros ciclos contemplem as unidades de saúde que já possuam interesse nestas práticas (e/ou profissionais capacitados), o que facilita a expansão da estratégia para outras unidades não tão sensibilizadas inicialmente. Na experiência de Florianópolis trabalhou-se com ciclos de 6 unidades de saúde, buscando uma representatividade por distrito sanitário. Nesta lógica, em cada ciclo as ações se solidificam e, em longo prazo, é possível que todas as unidades de saúde estejam com ações em PIC em curso e bem consolidadas. Paralelamente, o núcleo responsável segue com outras discussões/providências, como o estabelecimento de parcerias institucionais, provisão de recursos financeiros e organização de atividades de Educação Permanente em Saúde (EPS), esta entendida como uma proposta inovadora que busca adequar os processos de educação dos profissionais à realidade e à necessidade dos serviços de sáude ${ }^{34}$, podendo corresponder aos processos educativos relacionados à educação em serviço, educação continuada, educação formal de profissionais e, até mesmo, educação popular ${ }^{35}$.

\section{Etapa B - Pactuação \\ do plano local de implantação}

O estabelecimento de planos locais de implantação das PIC participativos, singularizados e adaptados às realidades locais dos serviços foi uma estratégia adequada, na avaliação da equipe do seminário de pesquisa de Florianópolis. Uma condição amplamente favorável para que uma pessoa ou organização decida mudar ou incorporar novos elementos à prática é a vivência e/ou reflexão sobre as experiências e desconfortos, de modo a gerar disposição para produzir transformações e se abrir para alternativas de práticas e de saberes ${ }^{35}$, refletindo em melhoria da qualidade ${ }^{31}$.

Para isso, sugere-se uma atividade denominada "Oficina de sensibilização em PIC - pactuação de ações", cujo objetivo é sensibilizar os trabalhadores da unidade de saúde sobre o tema, utilizando referenciais da educação crítico-reflexiva e dinâmica que fomenta a discussão no contexto da realidade local e, por fim, pactuar ações relacionadas às PIC a serem desenvolvidas naquela unidade. O Quadro 2 apresenta uma sugestão de roteiro, com duração total de quatro horas, divididas em cinco momentos. Nesta oficina é estimulada a participação de todos os trabalhadores da unidade, já que o vínculo e o sentimento de pertencer às intituições é mobilizado pelo desejo de participar e de reconhecimento identidário ${ }^{21} \mathrm{e}$, portanto, quanto maior o número de participantes mais caracteriza-se a pactuação de ações do grupo e não apenas ações individuais. Para a realização da oficina, a unidade de saúde permanece fechada por cerca de 4 horas, devendo a data ser definida antecipadamente com ampla divulgação à comunidade, incluindo prévia pactuação com o Conselho Local de Saúde, se houver.

O plano local de implantação das PIC é, então, produzido a partir de discussões que oportunizam a reflexão com base nas situações já vivenciadas ali, nas experiências de outras localidades e nas vivências individuais. Esta construção coletiva é fundamental para identificar as práticas e concepções vigentes e então problematizá-las no concreto do trabalho de cada equipe, incentivando a inovação $0^{36}$, e estabelecendo novos pactos de convivência e práticas, com vistas à atenção integral, humanizada e de qualidade ${ }^{35}$. É bastante provável que desta discussão coletiva e problematizadora surjam demandas de educação em serviço, tal como propõe a lógica ascendente da EPS, a partir dos problemas locais observados, considerando a necessidade de prestar cuidado relevante e de qualidade ${ }^{37}$. O quadro 3 apresenta um protótipo de documento final, representando o plano local de implantação das PIC de uma unidade de saúde, como resultado da oficina anteriormente sugerida, contendo: ações pactuadas, que a unidade se responsabiliza e é capaz de implantar; líderes de cada ação, que serão o contato com o núcleo responsável e estimularão o restante da equipe no cumprimento 
Quadro 2. Sugestão de Roteiro para Oficina Sensibilização em Práticas Integrativas e Complementares Pactuação do Plano Local de Implantação.

\begin{tabular}{|c|c|}
\hline \multicolumn{2}{|r|}{ Roteiro da Oficina } \\
\hline $\begin{array}{l}\text { Abertura } \\
(40 \mathrm{~min})\end{array}$ & $\begin{array}{l}\text { Distribuir o material de apoio. Realizar apresentação individual. Iniciar a } \\
\text { contextualização do tema } \mathrm{PIC}^{*} \text {, apresentação do } \mathrm{NR}^{* *} \text {, e a proposta da Oficina. }\end{array}$ \\
\hline $\begin{array}{l}\text { Discussão } \\
\text { de textos } \\
(50 \mathrm{~min})\end{array}$ & $\begin{array}{l}\text { Dividir os participantes em } 2 \text { a } 4 \text { subgrupos para leitura e discussão de textos trazidos } \\
\text { pelo NR sobre experiências exitosas em outros municípios, destacando os pontos mais } \\
\text { importantes e refletindo sobre a sua realidade. Após, cada subgrupo apresenta ao grande } \\
\text { grupo, compartilhando as reflexões e trazendo elementos para discussão no contexto de } \\
\text { seu município e sua unidade. }\end{array}$ \\
\hline $\begin{array}{l}\text { Dramatização } \\
\qquad(30 \mathrm{~min})\end{array}$ & $\begin{array}{l}\text { O grupo continua a discussão sobre as experências lidas e vivenciadas, seis voluntários são } \\
\text { chamados para que, sem que o grande grupo saiba, preparem uma dramatização livre } \\
\text { sobre uma situação do cotidiano da unidade envolvendo as PIC (uma consulta, um } \\
\text { grupo, uma visita, etc), utilizando adereços trazidos pelo NR para se caracterizar como } \\
\text { médico, enfermeiro, agente comunitário de saúde, usuários, etc. O objetivo é observar e } \\
\text { penetrar nos fenômenos, visualizando, de forma caricata, situações possíveis de serem } \\
\text { vivenciadas na unidade de saúde relacionadas às PIC e verificando a habilidade e empatia } \\
\text { dos profissionais em lidar com o tema, considerando o contexto sociocultural } \\
\text { apresentado. Após apresentação ao grupo, amplia-se a discussão sobre aquele situação } \\
\text { cotidiana: conduta profissional, infomações dos usuários, dificuldades e facilidades } \\
\text { encontradas, outros pontos de atenção observados. }\end{array}$ \\
\hline $\begin{array}{c}\text { Intervalo } \\
(20 \mathrm{~min})\end{array}$ & $\begin{array}{l}\text { Neste ponto da oficina a tendência é já haver um grande envolvimento de todos na } \\
\text { discussão de como poderiam implantar as PIC em sua unidade de saúde. Por isso, } \\
\text { recomenda-se fazer um pequeno intervalo. }\end{array}$ \\
\hline $\begin{array}{l}\text { Pactuação } \\
\text { de ações } \\
\text { em PIC } \\
\text { (1h20min) }\end{array}$ & $\begin{array}{l}\text { Retornar aos subgrupos e discutir que ações em PIC podem ser feitas na unidade, } \\
\text { baseado em todos elementos discutidos até então, pensando: "Qual ação? Quem fará? } \\
\text { Como? Onde? Quando? etc". Considerar a capacidade produtiva para desenvolver tal ação } \\
\text { e, sempre que houver limitações, apontar como poderiam ser solucionadas (ex: recursos } \\
\text { materiais, capacitações, etc). Consensuando as ações propostas pelo subgrupo, cada um } \\
\text { apresenta suas propostas ao grande grupo, que, após apresentação de todos subgrupos, } \\
\text { refletirá sobre quais ações são viáveis, quais podem ser integradas e quais de fato poderão } \\
\text { ser implantadas. Por fim, pactua-se com todos as ações a serem implantadas, lembrando } \\
\text { que a qualidade na execução de cada ação é preferivel à quantidade, e, para cada ação, } \\
\text { definir: líderes de cada ação; metas e indicadores relacionados à ação; cronograma de } \\
\text { implantação; organização do acesso e outras atividades necessárias. Todos estes dados } \\
\text { constarão no documento final da oficina (Plano Local de Implantação das PIC). }\end{array}$ \\
\hline $\begin{array}{l}\text { Finalização } \\
\text { da Oficina } \\
(20 \mathrm{~min})\end{array}$ & $\begin{array}{l}\text { Definir um membro do NR como tutor da unidade de saúde. O Plano Local de } \\
\text { Implantação das PIC é o documento final produzido pela oficina e norteador das ações a } \\
\text { serem implantadas. Entregar uma cópia deste documento a cada participante e anexar } \\
\text { uma cópia maior em local visível da unidade, a fim de retomar visualmente e } \\
\text { constantemente as ações pactuadas. Recomenda-se fazer uma pequena avaliação da } \\
\text { Oficina ao final. }\end{array}$ \\
\hline
\end{tabular}

* Práticas Integrativas e Complementares; * Núcleo Responsável

das ações; bem como indicadores, metas e outras atividades relacionadas.

\section{Etapa C - Viabilização de tutoria}

O objetivo da viabilização de tutoria é fomentar a realização e execução do plano local elabo- rado e obter permanência e sustentabilidade das PIC, valendo-se da pedagogia da EPS, para que as PIC façam sentido na realidade do serviço e operem processos significativos nela, rompendo com a tradicional vinculação de políticas ou programas específicos à uma linha de capacitações ou prescrições de trabalho aos profissionais, sem 
Quadro 3. Exemplo de Plano Local de Implantação das Práticas Integrativas e Complementares em uma Unidade de Saúde, como resultado da Oficina de Sensibilização em Práticas Integrativas e Complementares.

\begin{tabular}{|c|c|c|c|c|}
\hline \multicolumn{5}{|c|}{ Plano Local de Implantação - ações pactuadas em práticas integrativas e complementares } \\
\hline \multicolumn{5}{|c|}{ 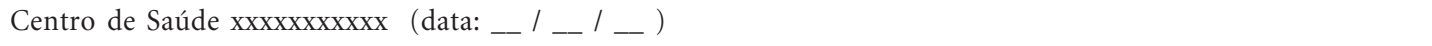 } \\
\hline \multicolumn{5}{|c|}{ 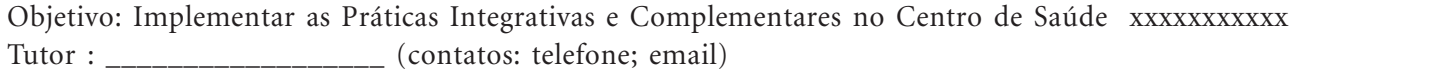 } \\
\hline Ação pactuada & Líder & Indicador & Início & Atividades relacionadas \\
\hline $\begin{array}{l}\text { Fortalecer a } \\
\text { Acupuntura }\end{array}$ & $\mathrm{xxxx}$ & $\begin{array}{l}\text { Número de } \\
\text { atendimentos por } \\
\text { semana }\end{array}$ & Imediato & $\begin{array}{l}\text { Legitimar profissional formado; Realizar } \\
\text { parceria para "Treinamento em Técnicas } \\
\text { de Acupuntura". }\end{array}$ \\
\hline \multirow[t]{3}{*}{$\begin{array}{l}\text { Desenvolver a } \\
\text { Fitoterapia }\end{array}$} & $\mathrm{xxxx}$ & $\begin{array}{l}\text { Número de grupos } \\
\text { na horta } \\
\text { medicinal por mês }\end{array}$ & $\begin{array}{l}\text { Após } \\
\text { construção } \\
\text { horta medicinal }\end{array}$ & Estruturar a horta medicinal \\
\hline & & $\begin{array}{l}\text { Percentual de } \\
\text { profissionais } \\
\text { sensibilizados }\end{array}$ & $\begin{array}{l}\text { Após Oficina } \\
\text { de } \\
\text { Sensibilização }\end{array}$ & $\begin{array}{l}\text { Realizar Oficina de sensibilização para } \\
\text { profissionais de nível médio e fundamental } \\
\text { da unidade e para comunidade. }\end{array}$ \\
\hline & & $\begin{array}{l}\text { Percentual de } \\
\text { profissionais } \\
\text { capacitados }\end{array}$ & $\begin{array}{l}\text { Após } \\
\text { capacitação }\end{array}$ & $\begin{array}{l}\text { Realizar parceria para "Treinamento em } \\
\text { Plantas Medicinais e Fitoterapia" para } \\
\text { profissionais de nível superior da unidade. }\end{array}$ \\
\hline $\begin{array}{l}\text { Implantar } \\
\text { grupos de } \\
\text { automassagem }\end{array}$ & $\mathrm{xxxx}$ & $\begin{array}{l}\text { Número de grupos } \\
\text { por mês }\end{array}$ & $\begin{array}{l}\text { Após } \\
\text { capacitação }\end{array}$ & $\begin{array}{l}\text { Realizar "Capacitação para Facilitadores } \\
\text { de Automassagem" }\end{array}$ \\
\hline $\begin{array}{l}\text { Implantar a } \\
\text { Auriculoterapia }\end{array}$ & $\mathrm{xxxx}$ & $\begin{array}{l}\text { Número de } \\
\text { atendimentos } \\
\text { por semana }\end{array}$ & $\begin{array}{l}\text { Após } \\
\text { capacitação }\end{array}$ & $\begin{array}{l}\text { Realizar "Capacitação em } \\
\text { Auriculoterapia"; Incluir o uso da técnica } \\
\text { na sala de espera e acolhimento. }\end{array}$ \\
\hline
\end{tabular}

oportunidade de assessoramento ${ }^{35}$. Deseja-se com a tutoria o oposto, ou seja, que o olhar, a escuta, a parceria e o apoio permitam compreender a especificidade e os problemas locais, com elaboração de estratégias adequadas ao seu enfrentamento. O tutor pode ser um representante ou membro do núcleo responsável e pode ser determinado na etapa anterior, juntamente com a elaboração do plano local das PIC. Essa tutoria aproxima-se da noção de "apoio" de $\operatorname{Campos}^{38}$, como uma pressão de fora, que implica trazer algo externo ao grupo que opera os processos de trabalho, sustentando e "empurrando" o outro. Esta proposta é importante na gestão participativa já que busca intervir de maneira interativa, partindo do pressuposto que as funções de gestão se exercem entre sujeitos com distintos graus de saber e de poder.
É comum que os líderes das ações pactuadas nos planos locais se envolvam suficientemente no cumprimento destas ações, passando a discutir com os demais colegas em diversos espaços (reuniões da unidade, reuniões de equipe, etc), e será principalmente com estes líderes que o tutor terá maior interface. Recomenda-se que se estabeleça um calendário de visitas e contatos do tutor com a unidade de saúde, podendo ampliar o intervalo entre as visitas conforme as ações passarem a ficar bem consolidadas. $\mathrm{Na}$ experiência base da pesquisa, o intervalo inicial entre as visitas foi de um mês, passando posteriormente para três, contando com a presença, ao menos, do coordenador da unidade e dos líderes das ações, em que se discutia as formas de apoio na execução das ações, com sugestões de atividades, parcerias e possibilidades de EPS. 
O tutor poderá utilizar as estratégias de apoio sugeridas por $\operatorname{Campos}^{38}$, como construir rodas e contribuir para a criação de espaços coletivos, aplicando metodologias que tragam ofertas externas e também valorizem as demandas do grupo, estimulando as decisões coletivas, o trabalho em equipe ${ }^{36}$ e orientando-se pelo plano local das PIC elaborado pela unidade. Após cada visita, o tutor retorna as demandas para a reunião periódica do núcleo responsável para que, juntamente com as demandas de outras unidades, defina-se um plano de ação para este ciclo de unidades, considerando as necessidades de EPS, fornecimento de materiais e insumos, viabilização de estrutura física, apoio matricial, etc.

\section{Etapa D - Atividades de apoio relacionadas à Educação Permanente em Saúde}

Baseado nas ações pactuadas no plano local de implantação das PIC de cada unidade de saúde e, ainda, nas demandas das unidades trazidas pelos tutores, o núcleo responsável elabora um plano de ação em que as atividades relacionadas à EPS merecem um maior destaque, a fim de suprir a deficiência de formação existente na graduação dos profissionais sobre as PIC, e que refletem os modelos conservadores, centrados em saberes e tecnologias biomédicas dependentes de procedimentos e equipamentos diagnósticos e terapêuticos ${ }^{39}$. A EPS relacionada às PIC é ainda mais complexa e, ao mesmo tempo, relevante, já que a presença de saberes tradicionais das culturas e a produção de sentidos ligada ao processo saúde-doença-cuidado-qualidade de vida pertencem a lógicas em grande parte distintas do modelo científico hegemônico vigente ${ }^{35}$. Para isso, deve-se refletir sobre desenvolver EPS contextualizada e utilizar outros espaços institucionais para além das tradicionais capacitações (que geram o esvaziamento de profissionais da rede), como reuniões de categoria profissional, reuniões da unidade de saúde, reuniões de equipe, entre outros, já que, conforme Ceccim ${ }^{35}$, as capacitações não se mostram eficazes para possibilitar a incorporação de novos conceitos e princípios às práticas estabelecidas, por trabalharem de maneira descontextualizada e se basearem principalmente na transmissão de conhecimentos.

Sugere-se que as atividades em EPS iniciem tão logo seja pactuado o plano local das PIC nas unidades de saúde contempladas no mesmo ciclo e, portanto, terão como público-alvo os profissionais daquelas unidades, facilitando a saída do serviço, já que são relativamente poucos os profissionais envolvidos, comparados a toda rede de serviços. O núcleo responsável poderá estabelecer um rol de atividades educativas, articulando-se à coordenação de EPS da secretaria, caso exista, e buscando outras parcerias, tendo como base os planos locais das unidade de saúde. Como exemplo, em Florianópolis planejou-se atividades de EPS relacionadas à fitoterapia (formação profissional em fitoterapia, oficinas de educação popular para a comunidade e agentes comunitários de saúde, oficinas de desenvolvimento de horta medicinal), já que todas as unidades de saúde do primeiro ciclo pactuaram "desenvolver a fitoterapia”, refletindo a realidade de uso generalizado desta terapia pela população mundial e $\operatorname{local}^{40}$. O núcleo responsável poderá apoiar-se na expertise dos profissionais mapeados, na Fase 2, para que sejam referências de ensino, com intuito de valorização do potencial dos próprios profissionais e também como estratégia de superação da carência de financiamento para as PIC; ou talvez sejam necessárias outras parcerias institucionais, que devem ser providenciadas e apoiadas pelo SUS, para que a EPS constitua espaços de planejamento, gestão e mediação ${ }^{37}$.

Ao fim do primeiro ciclo, é bem provável que as unidades de saúde estejam com as ações em PIC na APS bem consolidadas: possuem seu plano local de implantação pactuado; contam com tutoria permanente para execução das ações pactuadas; receberam atividades de EPS relacionadas às PIC a fim de favorecer a implantação e realização das ações. Assim, é chegado o momento de expansão para mais unidades de saúde e, conforme se perceba que há capacidade produtiva para iniciar um novo ciclo, novas unidades de saúde serão elencadas e todo o processo descrito na Fase 4 se iniciará novamente. As características de cada município e de sua gestão, bem como a disponibilidade e produtividade do núcleo responsável, definirão a velocidade de implantação das PIC nas unidades de saúde da APS.

\section{Considerações finais}

A inserção das PIC na APS configura uma ação de ampliação de acesso e qualificação dos serviços, na perspectiva da integralidade da atenção à saúde da população. Para sua consolidação, como mais uma estratégia terapêutica e promotora de saúde na APS, devem ser consideradas as 
diversas influências que interferem no decorrer deste processo: gestores, políticas institucionais, sujeitos envolvidos (e suas competências), cultura local e organizacional, etc. A realização de um processo guiado democraticamente, discutido e sustentado, promove o aperfeiçoamento e adequação das atividades e norteia as ações a serem implantadas. A coparticipação no estabelecimento de ações em PIC é tão importante quanto os resultados obtidos, refletindo em mudanças na percepção dos envolvidos e na cultura da própria instituição ${ }^{31}$. Nossa experiência, ainda em fase relativamente inicial e com resultados, portanto, parciais, vem indicando que o roteiro metodológico sintetizado parece defensável, sustentável e promissor. Sabe-se que a transformação nas práticas em saúde exige envolvimento de atores sociais, institucionais e profissionais e parece-nos que a estratégia proposta favorece o protagonismo e a participação dos profissionais, democratizando a gestão e ampliando a atenção à saúde, com responsabilização pactuada entre gestores, trabalhadores e usuários, como estimula a Política Nacional de Humanização. O método apresentado facilita o desenvolvimento de ações sólidas e sustentáveis, fomentando a gestão participativa, a construção da integralidade e a ampliação responsável e cuidadosa das práticas e saberes no cuidado, além de propiciar o registro de experiências, contribuindo para a implantação das PIC na APS.

\section{Colaboradores}

MC Santos trabalhou na concepção, coleta, registro e análises de dados, todos seminários de pesquisa, estudo bibliográfico, redação inicial, revisões e redação final. CD Tesser participou de todas as fases da pesquisa como orientador, incluindo participação em muitos seminários de pesquisa, e da redação inicial, revisões e final do artigo.

\section{Agradecimentos}

Aos membros da Comissão de Práticas Integrativas e Complementares da Secretaria Municipal de Saúde de Florianópolis (equipe de pesquisaação deste trabalho): Sônia de Castro S. Thiago; Daniela Baumgart de Liz Calderon; Leila Nery Santos de Souza; Gelso Guimarães Granada; Renato José Alves de Figueiredo e Ari Ojeda Ocampo Moré. 


\section{Referências}

1. Brasil. Ministério da Saúde (MS). Secretaria de Atenção à Saúde. Departamento de Atenção Básica. Portaria 971 - Política Nacional de Práticas Integrativas e Complementares (PNPIC) no Sistema Único de Saúde; Diário Oficial da União 2006; 03 maio.

2. Gonçalves RP, Antunes HM, Teixeira JBP, Cardoso LO, Barbosa PR. Profissionais da área de saúde pública: atitudes, conhecimentos e experiências em relação a práticas médicas não convencionais. Rev APS 2008; 11(4):398-405.

3. Nogales-Gaete J. Medicina alternativa y complementaria. Rev Chil Neuropsiquiatr 2004; 42(4):243-250.

4. Sayd JD. Novos Paradigmas e Saúde. Physis 1999; 9(1):113-121.

5. Tesser CD, Barros NF. Medicalização social e Medicina alternativa e complementar: pluralização terapêutica do sistema único de saúde. Rev Saude Publica 2008; 42(5):914-920.

6. Luz MT. Cultura contemporânea e medicinas alternativas: novos paradigmas em saúde no fim do século XX. Physis 2005; 15(Supl.):145-176.

7. Sousa IMC, Vieira ALS. Serviços Públicos de saúde e medicina alternativa. Cien Saude Colet 2005 10(Supl.):255-266.

8. Andrade JT. Medicinas alternativas e complementares: experiência, corporeidade e transformação. Salvador, Fortaleza: EDUFBA, EdUECE; 2006.

9. Levin JS, Jonas WB, organizadores. Tratado de medicina complementar e alternativa. São Paulo: Manole; 2001

10. Tesser CD, Luz MT. Racionalidades Médicas e integralidade. Cien Saude Colet 2008; 13(1):195-206.

11. Brasil. Ministério da Saúde (MS). Secretaria de Atenção à Saúde. Departamento de Atenção Básica. Coordenação Nacional de Práticas Integrativas e Complementares. Relatório de Gestão 2006/2010 Práticas Integrativas e Complementares no SUS. Brasília-DF: MS; 2011.

12. Helman CG. Culture, health and Ilness. $5^{\text {th }}$ Edition. New York: Oxford University Press; 2007.

13. Andrade JT, Da Costa LFA. Medicina complementar no SUS: práticas integrativas sob a luz da antropologia médica. Saude Soc 2010; 19(3):497-508.

14. De Simoni CL, Benevides I, Barros NF. As práticas Integrativas e Complementares no SUS: realidade e desaûos após dois anos de publicação da PNPIC. Rev Bras Saude Fam 2008; IX:72-76.

15. Barrett B, Marchand L, Scheder J, Plane MB, Maberry R, Appelbaum D, Rakel D, Rabago D. Themes of Holism, Empowerment, Access, and Legitimacy Define Complementary, Alternative, and Integrative Medicine in Relation to Conventional Biomedicine. J Altern Complement Med 2003; 9(6):937-947.

16. Thiollent M. Medotologia da Pesquisa-ação. 17a Edição. São Paulo: Cortez; 2009.

17. Thiollent M. Pesquisa-ação nas Organizações. São Paulo: Atlas; 1997.

18. McWhinney IR, Freeman T. Textbook of Family Medicine. $3^{\text {rd }}$ Edition. New York: Oxford University Press; 2009.

19. Ross J. An audit of the impact of introducing microacupuncture into primary care. Acupunct Med 2001; 19(1):43-45.
20. Ben-Arye E, Frenkel M, Klein A, Scharf M. Attitudes toward integration of complementary and alternative medicine in primary care: perspectives of patients, physicians and complementary practitioners. Patient Educ Couns 2008; 70(3):395-402.

21. Guizardi FL, Cavalcanti FO. O conceito de cogestão em saúde: reflexões sobre a produção de democracia institucional. Physis 2010; 20(4):1245-1265.

22. Campos GWS. O anti-Taylor: sobre a invenção de um método para co-governar instituições de saúde produzindo liberdade e compromisso. Cad Saude Publica 1998; 14(4):863-870.

23. Campos GWS. Um método para análise e co-gestão de coletivos. São Paulo: Hucitec; 2000.

24. Rivera FJU, Artmann E. Planejamento e gestão em saúde: flexibilidade metológica e agir comunicativo. Cien Saude Colet 1999; 4(2):355-365.

25. Barros NF. A construção da Medicina Integrativa: um desafio para o campo da saúde. São Paulo: Hucitec; 2008.

26. Queiroz MS. O itinerário rumo às medicinas alternativas: uma análise em representações sociais de profissionais da saúde. Cad Saude Publica 2000; 16(2): 363-375.

27. Hsio AF, Ryan GW, Hays RD, Coulter ID, Andersen RM, Wenger NS. Variations in provider conceptions of integrative medicine. Soc Sci Med 2006; 62(12):2973-2987.

28. Bell IR, Caspi O, Schwartz GE, Grant KL, Gaudet TW, Rychener D, Maizes V, Weil A. Integrative medicine and systemic outcomes research - Issues in the emergence of a new model for primary health care. Arch Intern Med 2002; 162(2):133-140.

29. Tesser CD. Práticas complementares, racionalidades médicas e promoção da saúde: contribuições poucos exploradas. Cad Saude Publica 2009; 25(8):1732-1742.

30. Tesser CD. Racionalidades médicas e integralidade: desafios para a Saúde Coletiva e o SUS. In: Pinheiro R, Silva Jr. AG, organizadores. Por uma sociedade cuidadora. Rio de Janeiro: CEPESC, IMS (UERJ), Abrasco; 2010. p. 77-100.

31. Marshall M, Sheaff R, Rogers A, Campbell S, Halliwell S, Pickard S, Sibbald B, Roland M. A qualitative study of the cultural changes in primary care organisations needed to implement clinical governance. Br J Gen Pract 2002; 52(481):641-645.

32. Campbel SM, Hann M, Hacker J, Burns C, Oliver D, Thapar A, Mead N, Gelb Safran D, Roland MO. Identifying predictors of high quality care in English general practice: observational study. BMJ 2001; 323(7316):1-6.

33. Costa AM, Lionço T. Democracia e Gestão Participativa: uma estratégia para a equidade em saúde? Saude Soc 2006; 15(2):47-55.

34. Haddad JQ, Roschke MAC, Davini MC. Educación permanente de personal de salud. Washington: Organización Panamericana de la Salud; 1994. p.1-30 (Serie de Desarrollo de Recursos Humanos, 100).

35. Ceccim RB. Educação Permanente em Saúde: desafio ambicioso e necessário. Interface Comun Saúde Educ 2005; 9(16):161-168. 
36. Bower P, Campbell S, Bojke C, Sibbald B. Team structure, team climate and the quality of care in primary care: an observational study. Qual Saf Health Care 2003; 12(4):273-279.

37. Ceccim RB, Feuerwerker LCM. O Quadrilátero da Formação para a Área da Saúde: Ensino, Gestão, Atenção e Controle Social. Physis 2004; 14(Supl.1): 41-64.

38. Campos GWS. Saúde Paidéia. São Paulo: Hucitec; 2003.

39. Feuerwerker LCM. Além do discurso de mudança na educação médica: processos e resultados. São Paulo: Hucitec; 2002.

40. World Health Organization (WHO). The World Medicines Situation 2011 - Tradicional Medicines: Global Situation, Issues and Challenges. Genova: WHO; 2011.

Artigo apresentado em 30/04/2012

Aprovado em 17/07/2012

Versão final apresentado em 30/08/2012 